\title{
Does stereotype threat affect creative thinking in female engineering students? A behavioral and neurocognitive study
}

\section{Dr. Rafal Jonczyk, (1) Adam Mickiewicz University; (2) Pennsylvania State University}

Rafał Jończyk (PhD) is an Assistant Professor of Linguistics at the Faculty of English of Adam Mickiewicz University in Poland. His main research interests concern the behavioural and neurocognitive correlates of emotion anticipation, perception, and production in the first (L1) and second (L2) language(s). His recent research interests include the investigation of brain dynamics during creative ideation and the extent to which creative ideation may be modulated by prior knowledge and training.

\section{Ms. Yushuang Liu, The Pennsylvania State University}

Yushuang Liu is a graduate student in Psychology and Language Science at Penn State. She is generally interested in natural speech processing using electroencephalogram. She has been actively involved in creativity projects examining how to facilitate divergent thinking abilities in engineering students.

\section{Dr. Danielle S. Dickson, Pennsylvania State University}

Dr. Dickson received her a Ph.D. from the University of Illinois at Urbana-Champaign in 2016 with a dissertation examining the memory system's representation of numerical information, using behavioral and electrophysiological (EEG, brainwaves) measures. She extended this work into comparisons of children and adults' arithmetic processing as a postdoctoral scholar at The University of Texas San Antonio. Presently, she is incorporating more flexible forms of creative thinking as an area of postdoctoral research at The Pennsylvania State University to contrast with more fact-based arithmetic numerical comprehension.

\section{Dr. Gül E. Okudan-Kremer, Iowa State University of Science and Technology}

Gül E. Kremer received her PhD from the Department of Engineering Management and Systems Engineering of Missouri University of Science \& Technology. Her research interests include multi-criteria decision analysis methods applied to improvement of products and systems. She is a senior member of IIE, a fellow of ASME, a former Fulbright scholar and NRC Faculty Fellow. Her recent research focus includes sustainable product design and enhancing creativity in engineering design settings.

\section{Prof. Zahed Siddique, University of Oklahoma}

Zahed Siddique is a Professor of Mechanical Engineering at the School of Aerospace and Mechanical Engineering of University of Oklahoma. His research interest include product family design, advanced material and engineering education. He is interested in motivation of engineering students, peer-to-peer learning, flat learning environments, technology assisted engineering education and experiential learning. $\mathrm{He}$ is the coordinator of the industry sponsored capstone from at his school and is the advisor of OU's FSAE team.

\section{Prof. Janet van Hell, Pennsylvania State University}

Janet van Hell (PhD, University of Amsterdam) is Professor of Psychology and Linguistics and CoDirector of the Center for Language Science at the Pennsylvania State University. She is interested in the neural and cognitive mechanisms underlying language processing in monolingual and bilingual children and adults, including creative language use. 


\section{Does stereotype threat affect creative thinking in female engineering students? A behavioral and neurocognitive study}

Undergraduate education is a formative and intellectually creative period during which students develop identities as STEM professionals capable of producing scientific knowledge and creating technological innovations. Although creativity and divergent thinking are among the key success ingredients for STEM professionals, little is known about underlying neurocognitive processing and its behavioral manifestations. The overarching goal of this NSF-funded research program is to examine the neural and cognitive mechanisms underlying creative thinking. A second goal is to examine how creative thinking is affected by factors in the educational and social context, with a specific focus on female engineering students. This paper reports a first study that examines how stereotype threat affects the neural correlates associated with creative thinking in female engineering students and the behavioral outcomes of their creative thinking. As will be discussed in more detail below, negative stereotypes of women's abilities have been identified as an important factor associated with the social-cultural environment that contribute to the low representation of women in certain STEM fields, such as engineering.

Although women have earned $57 \%$ of all bachelor's degrees since the late $1990 \mathrm{~s}$, the gender distribution is uneven across different fields [1]. For example, in 2012 women earned $70 \%$ of the U.S.'s bachelor's degrees in psychology, but only 19\% of the bachelor's degrees in engineering. Nationwide, the relatively low percentage of women engineering majors has remained stable over the past 15 years, even though other STEM fields (e.g., biology, chemistry, life sciences) have seen a steady and substantial gain in the percentage of women majors $[2,3]$. Gender gaps in STEM majors such as engineering have important societal and professional implications, because these fields miss out on potential contributions of talented women and on benefits of gender diversity within organizations, including greater creativity, innovation, and collective intelligence $[2,4,5,6]$.

Why are some STEM disciplines, such as engineering, not able to educate and graduate a higher number of women? In their review paper on differences in gender disparity across different STEM fields, Cheryan and colleagues [2] identified negative stereotypes of women's abilities as one of the two main factors associated with the social-cultural environment that contribute to the relatively low representation of women in certain STEM fields (the second factor is scarcity of relatable female role models). Moreover, undergraduate women majoring in engineering, computer science, or physics (STEM fields with the largest gender disparities) reported greater concerns about being stereotyped negatively because of their gender than women majoring in STEM fields with no or smaller gender disparities, such as biology [2].

One persistent stereotype of women's abilities relates to their perceived lack of creativity. Research has shown that men are perceived as being more creative than women, and individuals are more likely to associate creativity and innovative work behavior with men than with women $[7,8]$. In a series of five experiments, Proudfoot and colleagues [8] found that men and women tend to associate creative thinking with agentic qualities (e.g., daring, self-reliant) more typically ascribed to men than to women, and to judge men as more creative than women. For example, 
men were ascribed more creativity than women even though they produced identical output (Experiment 2) and female executives were evaluated as less innovative in their thinking than their male colleagues when evaluated by their supervisors (Experiment 4). Likewise, in complementary field and experimental studies, Luksyte and colleagues [7] observed that innovative work behaviors were stereotypically associated with men more than with women, and favorable performance evaluations were associated with innovative working behaviors for men, but not for women.

In the present research project, we investigated how creative thinking in female engineering students is affected by feedback expressing negative stereotypes in the form of a stereotype threat. Stereotype threat is a self-confirming belief that one may be evaluated based on a negative stereotype. Individuals targeted by this negative stereotype feel pressure to avoid being judged in light of the stereotype and worry that they inadvertently confirm it through their performance in that domain. Specifically, a US-based longitudinal study found that experiences of stereotype threat among women made them more likely to leave engineering, science, and mathematics majors [9]. Stereotype threat also impairs stereotyped students to build abilities [10] and undermines their test performance in the threatened domain [11], even if they have positive STEM attitudes [12]. For example, briefly referring to a person's gender prior to completing an ability test (e.g., intelligence, math) adversely affected test performance in women, consistent with typical stereotypes about the abilities of women in these domains [10, 12,13]. In the study reported here, engineering students completed creative thinking tasks while the electrical activity of their brain was recorded using electroencephalography (EEG). Halfway the experiment, the experimenter and a male undergraduate student-assistant delivered a stereotype threat. The critical question is to what extent female students' creative thinking is affected by a stereotype threat, as indexed by changes in behavioral and brain activity measures before and after the delivery of the stereotype threat.

\section{Experiment}

Twenty-seven female undergraduate students have in the experiment. They were asked to generate novel ideas to common objects (Alternative Uses Task) or come up with solutions to hypothetical situations (Utopian Situation Task) while their EEG was recorded to assess taskrelated changes in spectral power in the alpha frequency band [14]. Half of the items in both tasks related to engineering knowledge and half to general knowledge. Tasks and items were counterbalanced across participants using a Latin-square design.

Halfway the experiment, participants were allowed a short break, during which the male experimenter and a male undergraduate student entered the testing room and performed a scripted conversation with the female participant, which had the aim of inducing a stereotype threat. The stereotype threat was part of the conversation between the male experimenter, male undergraduate student, and female participant. The stereotype threat was modeled after the work of $[15,16,17]$, and expressed by the male undergraduate student as follows "We're looking how you're doing. What we've seen so far is that women tend to struggle with this task, so please try to do the task to the best of your ability after the break." After the experiment, participants answered manipulation check questions which verified the delivery of the stereotype threat. 
Electrophysiological data were continuously recorded in reference to electrode $\mathrm{FCZ}$ at a rate of $500 \mathrm{~Hz}$ from $30 \mathrm{Ag} / \mathrm{AgCl}$ active ActiCAP electrodes (Brain Products GmbH, Germany). EEG signals were amplified with a Neuroscan SynAmps2 amplifier unit (El Paso, TX) and filtered online with a band pass filter between 0.05 and $200 \mathrm{~Hz}$.

Behavioral results

The analysis of the behavioral data focused on ideational fluency (i.e., the number of generated ideas) in both the Alternative Uses Task and Utopian Situations Task, taking into account item type (engineering, non-engineering) as well as the impact of the stereotype threat by comparing idea generation pre- and post-threat implementation. A within-subject repeated measures ANOVA model (Item Type (engineering, non-engineering) $\times$ Stereotype Threat (before, after) $\times$ Task (Alternative Uses Task, Utopian Situations Task)) showed that in the Utopian Situations task, more ideas were generated for non-engineering items than for engineering items, but no such difference was obtained in the Alternative Uses Task. Importantly, the stereotype threat did not impact performance in either the Alternative Uses Task or the Utopian Situations Task.

Electrophysiological results

Based on previous work [18], we computed task-related power (TRP) changes in the lower and upper alpha band during creative ideation periods before and after the administration of the stereotype threat. Generally, with this technique, task-related power changes are assessed by contrasting the power in a given frequency band during a cognitive task with a preceding reference interval; power decreases from a reference to an activation interval are termed eventrelated desynchronization (ERD), and power increases are referred to as event-related synchronization (ERS). Event-related desynchronization and synchronization of the alpha band frequencies have been found to be especially sensitive to cognitive task performance and higher cognitive abilities, such as memory [19], language processing [20, 21], and creative idea generation [14]. Importantly, EEG alpha power has been found to vary as a function of creativity-related task demands and the originality of the idea. EEG alpha power has also been found to increase after interventions aiming to enhance creativity [14].

TRP values in the lower alpha band $(8-10 \mathrm{~Hz})$ and upper alpha band (10-12 Hz) were analyzed separately by means of two Repeated Measures (RM) ANOVA, with Stereotype threat (pre vs. post), Hemisphere (left vs. right) and Channel location (6 per each hemisphere: fronto-anterior left hemisphere (electrodes: FP1, F3, F7), fronto-anterior right hemisphere (electrodes: FP2, F4, F8), fronto-central left hemisphere (electrodes: FC1, FC5), fronto-central right hemisphere (electrodes: FC2, FC6), centro-temporal left hemisphere (electrodes: C3, T7), centro-temporal right hemisphere (electrodes: C4, T8), centro-parietal left hemisphere (electrodes: CP1, CP5), centro-parietal right hemisphere (electrodes: CP2, CP6), parietal left hemisphere (electrodes: P3, P7), parietal right hemisphere (electrodes: P4, P8), parieto-occipital left hemisphere (electrodes: PO9, O1), parieto-occipital right hemisphere (electrodes: PO10, O2)), as within-subject variables.

The RM ANOVA in the lower alpha band revealed greater alpha event-related synchronization (ERS) in the right compared to the left hemisphere channels. Importantly, the effect of threat was 
also significant, with more increased alpha-ERS in the post-threat than the pre-threat part of the experimental task. This increased alpha-ERS in the post-threat compared to the pre-threat condition occurred across all channel locations; increased alpha-ERS after intervention has been associated with enhanced creativity [18] and/or increased internal attention demands ('reliving' the threat in the mind's eye; [22]). The RM ANOVA in the upper alpha band reported similar results. There was greater ERS in the right than in the left hemisphere. Hence, also in the upper alpha frequency band there was increased alpha-ERS during ideation in the post-threat relative to the pre-threat condition, signifying enhanced creativity and/or increased internal attention demands in ideation after the stereotype threat.

Conclusion

The behavioral findings indicate that the stereotype threat did not affect the number of ideas female students generated (i.e., ideational fluency) in the Alternative Uses Task and the Utopian Situations Task. Interesting, brain activity associated with ideation during these tasks showed an increase in task-related power (TRP) changes in the lower and upper alpha frequency bands after the delivery of the stereotype threat. Building on earlier research [18] that found that EEG alpha power increases as fluency and originality of ideas generated during the Alternative Uses Task increases, the neurocognitive findings suggest that the stereotype threat boosted rather than restrained creative thinking in females. Alternatively, stereotype threat may have increased internal attention demands by means of reliving the threat in the participants' minds [22]. These alternative explanations will be further tested in future experimentation.

\section{Acknowledgements}

The work reported in this paper has been supported by NSF grants DUE 1561660 to Zahed Siddique and Janet van Hell, and DUE IUSE 1726811 to Janet van Hell, 1726358 to Zahed Siddique, and 1726884 to Gül E. Kremer.

\section{References}

[1] Women, minorities, and persons with disabilities in Science and Engineering, 2015. Internal report, National Science Foundation, National Center for Science and Engineering Statistics, Directorate for Social, Behavioral, and Economic Sciences.

[2] S. Cheryan, S. A. Ziegler, A. K. Montoya, and L. Jiang, "Why are some STEM fields more gender balanced than others?" Psychological Bulletin, vol. 143, pp. 1-35, 2017.

[3] B. Yoder. Engineering by the numbers. Internal publication of the American Society for Engineering Education. Retrieved from: www.asee.org, 2014.

[4] S. E. Page, The difference: How the power of diversity creates better groups, firms, schools, and societies. Princeton, NJ: Princeton University Press, 2007.

[5] E. Seymour and N. M. Hewitt, Talking about leaving: Why undergraduates leave the sciences. Boulder, CO: Westview Press, 1997.

[6] A. W. Woolley, C. F. Chabris, A. Pentland, N. Hashmi, and T. W. Malone, "Evidence for a collective intelligence factor in the performance of human groups," Science, vol. 330, pp. 686-688, 2010. 
[7] A. Luksyte, K. L. Unsworth, and D. R. Avery, "Innovative work behavior and sex-based stereotypes: Examining sex differences in perception and evaluations of innovative work behavior," Journal of Organizational Behavior, vol. 39, pp. 292-305, 2018.

[8] D. Proudfoot, A. C. Kay, and C. Z. Koval, "A gender bias in the attribution of creativity: Archival and experimental evidence for the perceived association between masculinity and creative thinking," Psychological Science, vol. 26, pp. 1751-1761, 2015.

[9] M. A. Beasley and M. J. Fischer, "Why they leave: The impact of stereotype threat on the attrition of women and minorities from science, math and engineering majors," Social Psychology of Education, vol. 15, pp. 427-448, 2012.

[10] M. Appel and N. Kronberger, "Stereotypes and the achievement gap: Stereotype threat prior to test taking," Educational Psychology Review, vol. 24, pp. 609-635, 2012.

[11] S. J. Spencer, C., Logel, and P. G. Davies, "Stereotype threat," Annual Review of Psychology, vol. 67, pp. 415-437, 2016.

[12] J. R. Shapiro and A. W. Williams, "The role of stereotype threats in undermining girls' and women's performance and interest in STEM fields," Sex Roles, vol. 66, pp. 175-183, 2012.

[13] C. Logel, G. M. Walton, S. J. Spencer, E. C. Iserman, W. von Hippel, and A. E. Bell, "Interacting with sexist men triggers social identity threat among female engineers," Attitudes and Social Cognition, vol. 96, pp. 1089-1103, 2009.

[14] A. Fink, M. Benedek, R. H. Grabner, B. Staudt, and A. C. Neubauer, "Creativity meets neuroscience: Experimental tasks for the neuroscientific study of creative thinking," Methods, vol. 42, pp. 68-76, 2007.

[15] H. J. Johnson, L. Barnard-Brak, T. F. Saxon, and M. K. Johnson, "An experimental study of the effects of stereotype threat and stereotype lift on men's and women's performance in mathematics," The Journal of Experimental Education, vol. 80, pp. 137-149, 2012.

[16] G. Adams, D. M. Garcia, V. Purdie-Vaughns, and C. M. Steele, C. M., "The detrimental effects of a suggestion of sexism in an instruction situation," Journal of Experimental Social Psychology, vol. 42, pp. 602-625, 2006.

[17] S. J. Spencer, C. M. Steele, C. M. and D. M. Quinn, "Stereotype threat and women's math performance," Journal of Experimental Social Psychology, vol. 35, pp. 4-28, 1999.

[18] A. Fink, and M. Benedek, "EEG alpha power and creative ideation," Neuroscience \& Biobehavioral Reviews, vol. 44, pp. 111-123, 2014.

[19] W. Klimesch, "EEG alpha and theta oscillations reflect cognitive and memory performance: a review and analysis," Brain Research Reviews, vol. 29, pp. 169-195, 1999.

[20] I. Bakker, A. Takashima, J. G. Van Hell, G. Janzen, and J. M. McQueen, "Changes in Theta and Beta Oscillations as Signatures of Novel Word Consolidation," Journal of Cognitive Neuroscience, vol. 27, pp. 1286-1297, 2015.

[21] M. C. M. Bastiaansen, A. Mazaheri, and O. Jensen, "Beyond ERPs: Oscillatory neuronal dynamics," in The Oxford Handbook of Event-Related Potential Components. S. J. Luck and E. S. Kappenman, Eds., Oxford University Press: New York, NY, pp. 31-50, 2012.

[22] M. Benedek, "The neuroscience of creative idea generation," in Exploring Transdisciplinarity in Art and Sciences, Z. Kapoula, E. Volle, J. Renoult, and M. Andreatta, Eds. Springer International, 2018, pp. 31-48. 